\title{
Post Underwater Wet Welding Heat Treatment by Underwater Wet Induction Heating
}

\author{
This paper presents the results of exploratory research into postweld \\ underwater electromagnetic induction heating
}

BY E. C. P. PESSOA, A. Q. BRACARENSE, V. R. DOS SANTOS, R. R. MARINHO, H. L. ASSUNÇÃO, AND F. C. RIZZO

\begin{abstract}
Wet welding procedures of Class A structural ship steels frequently fail to comply with the American Welding Society (AWS) D3.6M, Underwater Welding Code, in the maximum hardness criterion for the heat-affected zone (HAZ). The maximum hardness accepted in a welded joint is $325 \mathrm{HV}$ for higher-strength steel (yield strength > $350 \mathrm{MPa}$ ). In multipass welds, this problem occurs frequently and is restricted to the HAZ of the capping passes. The HAZ of the root and filling passes are softened by the reheating promoted by their respective subsequent passes. This paper presents the results of exploratory research into postweld underwater electromagnetic induction heating. The objective of the research was to evaluate the ability of induction heating to soften the specific high-hardness HAZs in underwater conditions. The results showed that this technique could reduce the maximum HAZ hardness of low-carbon structural ship steel welds to values below $325 \mathrm{HV}$, which is the maximum accepted by AWS for Class A welds. The induction-heated zone reached a maximum depth of about 10 $\mathrm{mm}$, which is considered adequate to treat the HAZ of capping passes in underwater wet welds.
\end{abstract}

\section{KEYWORDS}

- Shielded Metal Arc Welding (SMAW) • Wet Welding

- Heat-Affected Zone (HAZ) • Hardness Control

- Underwater Welding • Induction Heating

- Covered Electrodes • Oxyrutile Electrodes

\section{Introduction}

Underwater wet welding (UWW) trials have been carried out at depths of 10 m (Refs. 1-3) to verify whether the mechanical properties of welded joints met the main requirements of the American Welding Society (AWS) D3.6M, Underwater Welding Code, Class A (Ref. 4). The trials in Pessoa et al. (Ref. 2) and dos Santos et al. (Ref. 3) applied an oxyrutile-type, electrode-to-weld multipass V-butt and fillet joints using base metal (BM) steels with a carbon equivalent
(CE) varying between 0.32 and $0.39 \%$. At a water depth of $10 \mathrm{~m}$, the diffusible hydrogen content deposited by this electrode was about $20 \mathrm{~mL} / 100 \mathrm{~g}$, the weld metal (WM) porosity was about $0.5 \%$, and the elongation values were higher than 15\% (Ref. 3). There were two requirements of the AWS Code that were not met in the majority of the welded joints (Ref. 2): 1) maximum hardness limit in the heat-affected zone (HAZ) and 2) total approval in the bending tests.

The maximum hardness value accepted for Class A welds is $325 \mathrm{HV}$ when the BM is a high-strength ship steel (yield strength $>350 \mathrm{MPa}$ ). The high hardness values frequently found in the HAZ of wet welds is caused by the association of high hardenability of the BM with high cooling rates typical of wet welding (Refs. 5-8). Researchers reported $\Delta \mathrm{t}_{8 / 5}$ in the range of 2.5 to $3 \mathrm{~s}$ (Refs. 9-11), which is 10 to 15 times faster than dry welds.

In multipass welds, this problem occurs frequently and is always restricted to the HAZ of the capping passes because the HAZ of the root and filling passes are softened by the reheating promoted by subsequent passes. The unaltered coarse grain heat-affected zone (CGHAZ) of the final capping pass is normally where the highest hardness occurs. This region is also the most susceptible to cold cracks due to the coarse martensite microstructure and the lack of tempering (Refs. 1, 12).

The hardness of the underwater wet welded HAZ depends directly on the $\mathrm{CE}$ of the $\mathrm{BM}$ because the cooling rates in this situation are always high enough to harden the HAZ of the joint (Refs. 5, 7, 8). To comply with the maximum hardness limit of the AWS Code, a reliable temper-bead (TB) technique or local postweld heat treatment (PWHT) must be applied (Ref. 5).

Only a few papers concerning local underwater softening heat treatments can be found. For example, systems applying a hydrogen-oxygen cutting torch as the heating device or a jet-heating gun (underwater high-velocity, oxygen-fuel thermal spraying system) along the weld bead have already been tested successfully under exploratory conditions (Refs. 13, 14). Laser applications have also been attempted (Refs. 15, 16). Nevertheless, applications of industrial or extensive underwater in-situ heat treatments are unknown.

The most common technique studied and applied to re- 
duce the hardness of the HAZ, and consequently improve the weldability of high-strength steels, is the TB technique (Refs. 13, 17, 18).

Fydrych et al. (Ref. 18) simulated the TB technique in steel plates with $0.37 \mathrm{CE}$. The welds were made in a water depth of $0.5 \mathrm{~m}$ using rutile electrodes. The hardness measurements showed a reduction from 450 to 300 HV10 when the pitch value (overlap) between subsequent beads varied between 55 and $100 \%$. The authors stated this technique is limited by the repeatability of the process in underwater applications due to the high number of factors that need to be controlled.

Fydrych et al. (Ref. 19) studied the weldability of highstrength steels with a CE of 0.3 and 0.4 in wet welding conditions. They found a HAZ hardness of about $280 \mathrm{HV} 10$ in the $0.3 \mathrm{CE}$ steel. For the $0.4 \mathrm{CE}$, the values reported were more than $400 \mathrm{HV} 10$. All the Tekken tests performed underwater for both steels presented cracks. Rogalski et al. (Ref. 20) studied a UWW repair at a depth of $0.5 \mathrm{~m}$ on an API 5L X65 pipe with a CE of 0.43. Pipes were welded under two conditions: insulated from water and noninsulated from water. Hardness measurements were performed at the critical point of the HAZ (close to the surface exposed to the water). The results measured ranged from 300 to $318 \mathrm{HV} 10$ in the insulated pipe specimens, and they reached maximum values of 386 and 385 HV10 in the noninsulated specimens.

Recently, Fydrych et al. (Ref. 21) studied the impact of heat input (HI) on the weldability of high-strength steels with a $C E$ of 0.38 . Controlled thermal severity test joints were produced at a water depth of $0.2 \mathrm{~m}$ using $4.0-\mathrm{mm}$ diameter rutile electrodes. The HI varied between 1.3 and $1.9 \mathrm{~kJ} / \mathrm{mm}$. The hardness values found were in the range of 370 to $460 \mathrm{HV} 10$. No correlation between HI and maximum hardness in the HAZ was found.

Li et al. (Ref. 22) explored the same topic of HI for arc stability and weld quality in underwater wet flux cored arc welding of E40 steel (CE of 0.41). Bead-on-plate (BOP) welds and joints were produced at a water depth of $0.5 \mathrm{~m}$, and the the $\mathrm{HI}$ varied from 16 to $39 \mathrm{~kJ} / \mathrm{cm}$. The authors concluded the HI had a limited effect on the hardness of the CGHAZ although the $\Delta \mathrm{t}_{8 / 5}$ cooling time increased from 3.2 to $7.9 \mathrm{~s}$. The hardness values in the CGHAZ were about $400 \mathrm{HV}$ for all conditions tested.

Gao et al. (Ref. 12) performed studies at a depth of 0.5 $\mathrm{m}$ using S355 steel (CE of 0.39) and with a HI ranging from 0.8 to $2.5 \mathrm{~kJ} / \mathrm{mm}$. The authors found that increasing the $\mathrm{HI}$ resulted in an increase in the $\Delta \mathrm{t}_{8 / 5}$ cooling time from 1.5 to $4.9 \mathrm{~s}$. The increment in the cooling time resulted in different CGHAZ microstructures. Lower HIs produced only lath martensite in the CGHAZ while higher HIs produced small amounts of upper bainite beside the predominant lath martensite. The maximum hardness measured in the CGHAZ at $0.8 \mathrm{~kJ} / \mathrm{mm}$ was $417 \mathrm{HV} 5$, and this decreased to 396 and $376 \mathrm{HV} 5$ at 1.5 and $2.5 \mathrm{~kJ} / \mathrm{mm}$, respectively. The authors also concluded the welds didn't meet the requirements for Class A and B welds, according to the AWS D3.6M Code (Ref. 4) and "the prevention of rapid cooling by increasing welding HI was not effective."

The use of real-time, induction-heat-assisted UWW was investigated by Zhang et al. (Ref. 23) in 2015 with the aim of increasing the HI during UWW. The industrial or in-situ application of this technique depends on automated systems that have not yet been developed. A reduction of the HAZ hardness values from 425 to $300 \mathrm{HV}$ was reported when an output voltage of $350 \mathrm{~V}$ was applied to the back side of a plate by induction heating during the welding procedure. The results were interesting because the method reduced the hardness to $325 \mathrm{HV}$, as required by the AWS D3.6M Code for Class A welds (Ref. 4).

In 2016, Pessoa et al. (Ref. 1) performed an exploratory study on underwater wet induction heating to observe the temperature distribution in a steel plate at the region just below the coil. An AISI 4340 steel plate, water quenched from $850^{\circ} \mathrm{C}$, was used as the BM. An $18-\mathrm{kW}$ induction variable power source coupled with an oval inductor (coil) with a field concentrator was able to induce temperatures in the austenite field at the points closest to the coil. This underwater wet procedure reduced the hardness from $636 \mathrm{HV}$ at the hardest point to $361 \mathrm{HV}$. The HAZ reached about $10 \mathrm{~mm}$ into the steel plate. The presence of a semielliptic-shaped martensitic area near the surface of the plate, right under the coil, indicated the temperatures reached values above the austenitic transformation temperature.

In 2019, Brätz et al. (Ref. 24) developed an induction heating technology that was able to run an inductor at welding speed in a fully mechanized underwater welding system. They investigated the effect of the HI on underwater welds and attempted to carry out underwater shielded metal arc welding (SMAW) with simultaneous inductive heating as well as leading and trailing inductive heating. They reported that both the hardness and the hydrogen content could be reduced by running an inductor at welding speed along the weld bead. Induction technology in fully mechanized SMAW systems allows heat management control by actively controlling the energy input.

Brätz et al. (Ref. 24) also performed occupational safety tests, which included measuring the electromagnetic field strength near the inductor. The authors stated, "There is no health risk to the diver performing the exercise." They also checked the practical side of induction technology with welding divers who manually performed the inductive heat treatments. The authors reported the divers were able to manually handle the inductor in the diving pool safely. The authors also reported a gradual reduction in the hydrogen concentration with increased warming time. The heat development and distribution were measured, and uniform heating over the cross section of a $10-\mathrm{mm}$-thick plate was achieved with a $16-\mathrm{kW}$ induction system with temperatures in the range of $100^{\circ}$ to $400^{\circ} \mathrm{C}$.

The use of the TB welding technique is theoretically reasonable but can be unreliable and unreproducible considering the poor visibility and other restraints typical of manned underwater activities (Ref. 18). Furthermore, the results of the aforementioned studies indicated the HI control has a limited role in reducing the hardness of the CGHAZ. As a result, there is consistent evidence that these two techniques (TB and HI control) commonly applied in dry welding to reduce hardness of the HAZ are not suitable under UWW conditions.

All methods reported in the literature are able to soften the HAZ of wet welds but only at very specific conditions and with serious limitations. 


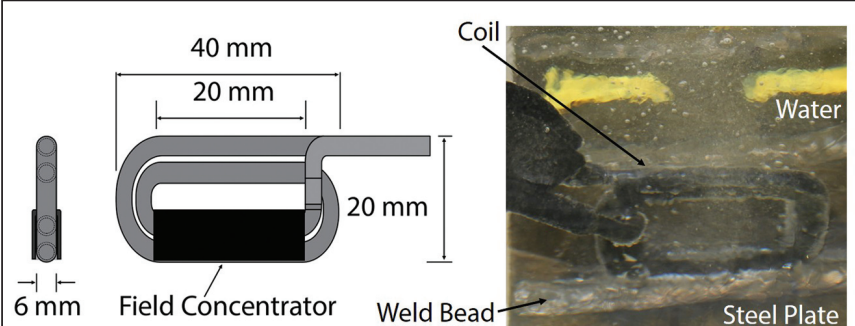

Fig. 1 - Inductor coil with dimensions (left) and underwater (right).

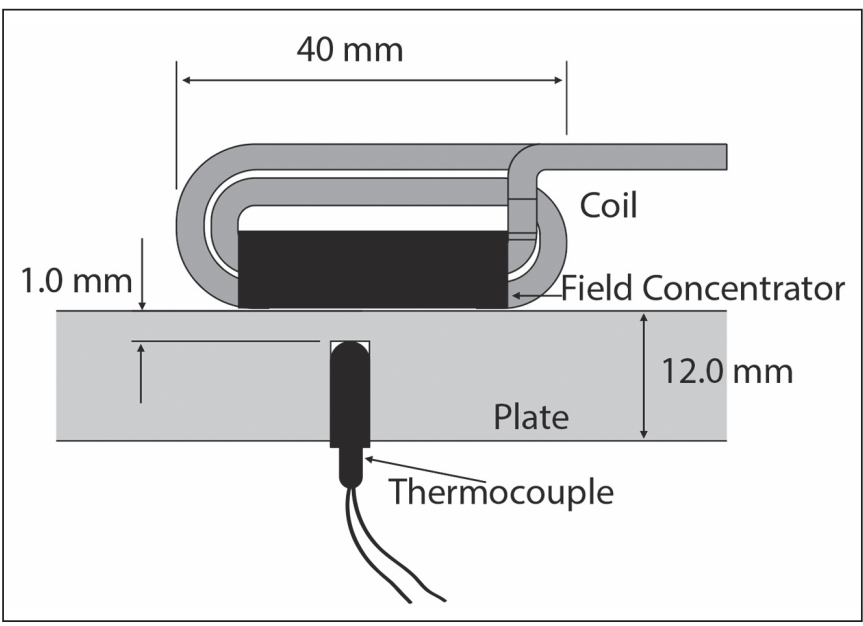

Fig. 3 - Schematic of the Type 1 experiments used to measure the thermal cycles and maximum steady temperature.

Flame-based processes present lower productivity due to the low travel speed and water depth limitations of acetylene (7.5-m limit) or the max pressures allowed for fuel gases, such as hydrogen. Other serious limitations are the impossibility of carrying out precise joint temperature control, torch positioning, and travel speed by the operator. The jetheating gun (Ref. 13) has a low travel speed $(4.0 \mathrm{~cm} / \mathrm{min}$ maximum), and it is difficult to control the distance between the nozzle and the welded plate as well as the travel speed.

In summarizing, it is possible to say the methods reported in the literature do not have techniques to control the holding temperature, holding time, and cooling rate of the HAZ. Controlling these three parameters is essential for any practical PWHT (Refs. 25, 26). The use of lasers and automated induction heating systems in the back of the plate, or moving together with the torch/electrode, significantly increases the complexity of the process, and its practical application is presently far from being a reality.

Therefore, because there is no industrial underwater wet PWHT that can be effectively applied nowadays, the promising results presented in the primary attempts performed underwater on hardened plates (Ref. 1) with induction heating can be applied to develop a method that is integrated with the UWW techniques used today. After depositing a weld bead, the diver/welder places an inductor/coil on the toe of the weld. In sequence, the surface cabin operator turns on the high-frequency source with all the induction parameters programed, such as power, frequency, and time.

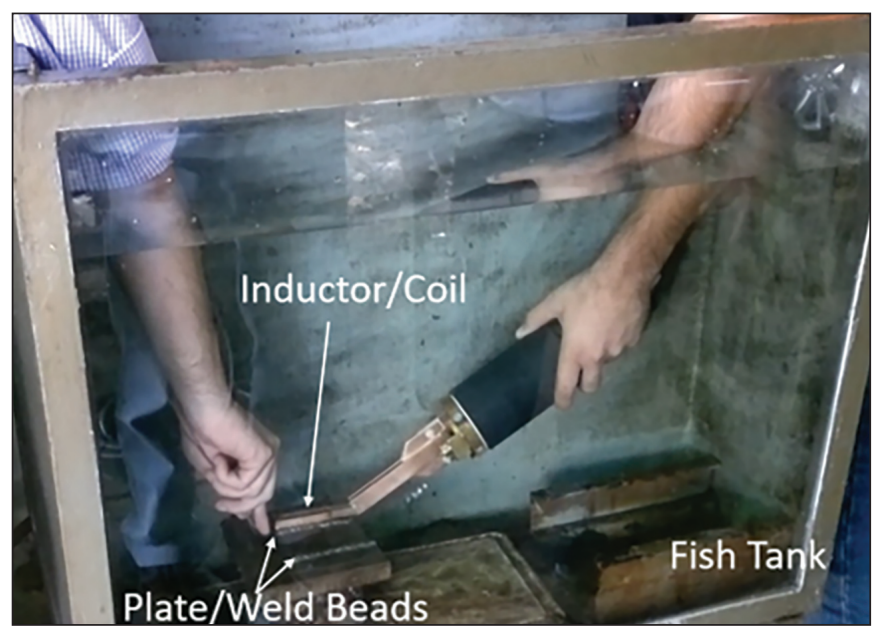

Fig. 2 - The setup used to perform PWHT under wet conditions.

The proposed method enables a region of the HAZ in the underwater wet welded joint to be exposed to a complete heat treatment cycle with fine control of the holding temperature, holding time, and cooling rate.

This paper describes the development of this method, which is able to control the HAZ hardness of underwater wet welds.

\section{Experimental Methods}

A variable induction power source with an $18-\mathrm{kW}$ power maximum, adjustable time, and induction frequency was specially developed by IMC Soldagem. A 40-mm-long and 6-mm-wide oval inductor coil containing two turns with a field concentrator prepared for underwater operations was used - Fig. 1. The inductor was placed directly in contact with the plate with no gap. All underwater wet PWHTs were performed at a water depth of $300 \mathrm{~mm}$. Figure 2 shows an inductor/coil and plate with weld beads set up in a fish tank.

The frequency was kept constant at $25.5 \mathrm{kHz}$ because the resonance frequency of the inductor coil allowed for the maximum permeability and deepest heating into the plate.

Figures 3-5 show the schematics of the three types of experiments performed. Figure 3 depicts Type 1 , with measurements of the thermal cycles at a 1-mm plate depth with both normal and controlled cooling rates. Figure 4 illustrates Type 2, with hardness measurements in the HAZ of BOP welds at different distances from the contact surface of the plate and coil. Figure 5 shows Type 3, with coil positioning and hardness measurements in the V-groove welds. Hardness measurements were made according to the AWS D3.6M Code recommendations for Class A procedure qualifications (Ref. 4). A structural ship steel ASTM A131-8 grade AH36 steel, whose chemical composition is presented in Table 1, was used as the BM for the Type 1 and 2 experiments. The same type of steel was used in the Type 3 experiment but with a different chemical composition.

\section{Type 1 Experiments}

A $200 \times 100 \times 12$-mm plate was instrumented with $\mathrm{K}$ - and S-type thermocouples welded onto the bottom of holes drilled 


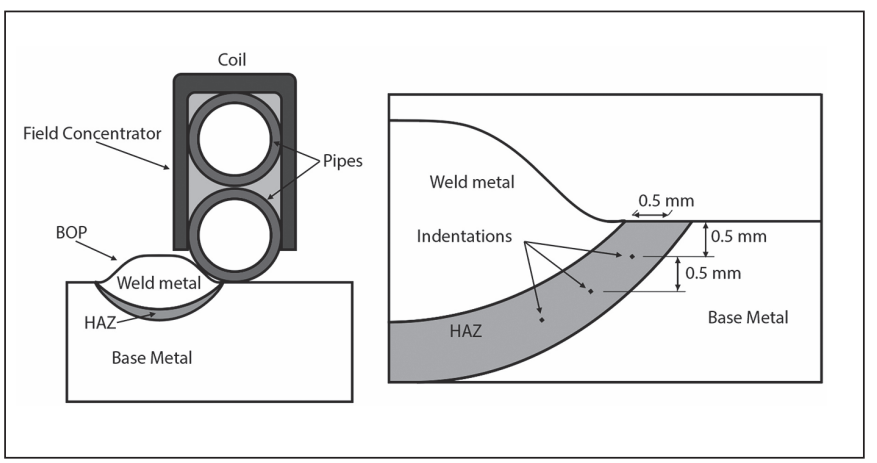

Fig. 4 - Schematic of the Type 2 experiments used to perform hardness measurements in cross sections of the HAZ of underwater wet welded BOP welds.

from the back of the plate at a distance of $1 \mathrm{~mm}$ from the surface - Fig. 3. The temperature was monitored so that the applied power could be correlated to the maximum stable temperatures achieved at this specific distance as a function of time. Initially, the maximum temperatures were determined for the following five power values: $7,10,13,15.5$, and $18 \mathrm{~kW}$. The so-called holding temperature is the steady-state temperature observed at a depth of $1 \mathrm{~mm}$ in a 12-mm-thick low-carbon steel plate submitted to an induction heating cycle - Fig. 3. The acquisition data system was shut off after $60 \mathrm{~s}$.

To avoid the formation of hard microstructures, a cooling ramp was programmed in the induction source software. The cooling ramp operation used here applied a linear power reduction from the maximum power to $0 \mathrm{kw}$ (shutting off the system). Figure 3 shows how the temperatures were measured. The heating power of $13 \mathrm{~kW}$ was then used with five different cooling ramps, which resulted in cooling times to room temperatures of $0,5,10,20$, and $30 \mathrm{~s}$, respectively. The $\Delta \mathrm{t}_{8 / 5}$ values were measured from the temperature vs. time curves.

\section{Type 2 Experiments}

The application of the underwater induction postweld heat treatment (UIPWHT) to the HAZ of a typical structural steel was tested. BOP weldments were deposited by a gravity feed system in wet underwater conditions at a m equivalent depth of $10 \mathrm{~m}$ on an ASTM AH36 steel plate using an ESAB WW70 commercial wet welding oxyrutile-type electrode with a 3.25-mm-diameter rod. The chemical composition of the $\mathrm{BM}$ is shown in Table 1 (only main elements are listed).

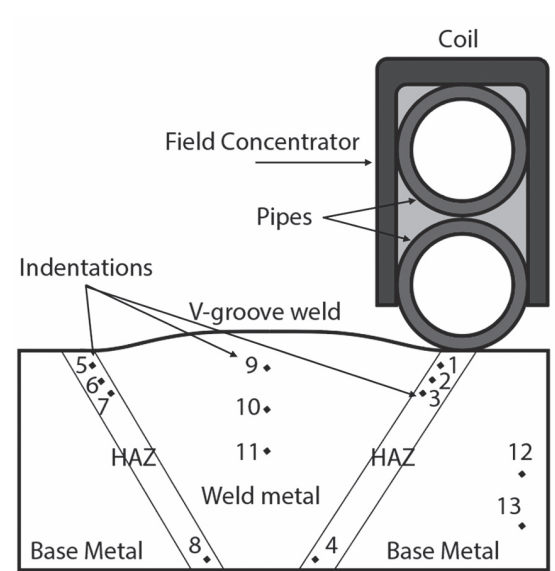

Fig. 5 - Schematic of the Type 3 experiments used to perform hardness measurements in cross sections of the underwater wet multipass V-groove butt welds.

The CE was calculated according to the formula from the International Institute of Welding. The time spent (holding time) in the postweld treatment can have a significant influence on the total diving time. Based on this assumption, the following two temperature ranges were considered: 1) Below critical temperature (avoiding austenitization but applying longer holding times), and 2) above critical temperature (applying shorter holding times).

In the first situation, no phase transformation occurred, and the HAZ softening was driven by tempering. In the second situation, a ferrite/cementite-to-austenite transformation occurred; therefore, it was necessary to control the cooling rate to avoid martensite formation during the fast cooling (quenching) presented in the aqueous environment.

The heat treatment procedures were performed by placing the coil in contact with the welding toe (HAZ) of a single BOP weld - Fig. 4. Power and time were varied. Three cross-sectional samples were removed from each heat-treated BOP weld, and five different BOP welds were deposited on two different plates. The two sets of BOP welds deposited on Plates 1 and 2 were used to study the effects of the different maximum steady temperatures (holding temperatures) and induction times (holding times) at maximum steady temperatures on the HAZ hardness at different depths in the plate.

All of the samples were prepared metallographically following the standard grinding and polishing procedures as

Table 1-Chemical Composition of the Base Metal and Weld Metal (wt-\%) Used in the Type 1, 2, and 3 Experiments

Type 1 and 2 Experiments

$\begin{array}{lccccccc} & \mathrm{C} & \mathrm{Mn} & \mathrm{P} & \mathrm{S} & & \mathrm{Si} & \mathrm{Al} \\ \text { Certificate } & 0.181 & 1.38 & 0.014 & 0.005 & 0.327 & 0.039 & 0.420 \\ \text { Measured } & 0.167 & 1.27 & 0.009 & 0.004 & 0.292 & 0.031 & 0.385\end{array}$

Type 3 Experiments

$\begin{array}{lcccccc} & \mathrm{C} & \mathrm{Mn} & \mathrm{Si} & \mathrm{Mo} & \mathrm{Ni} & \\ \text { Base Metal } & 0.13 & 0.98 & 0.296 & - & - & 0.30 \\ \text { Weld Metal } & 0.038 & 0.035 & 0.029 & 0.213 & 2.72 & -\end{array}$




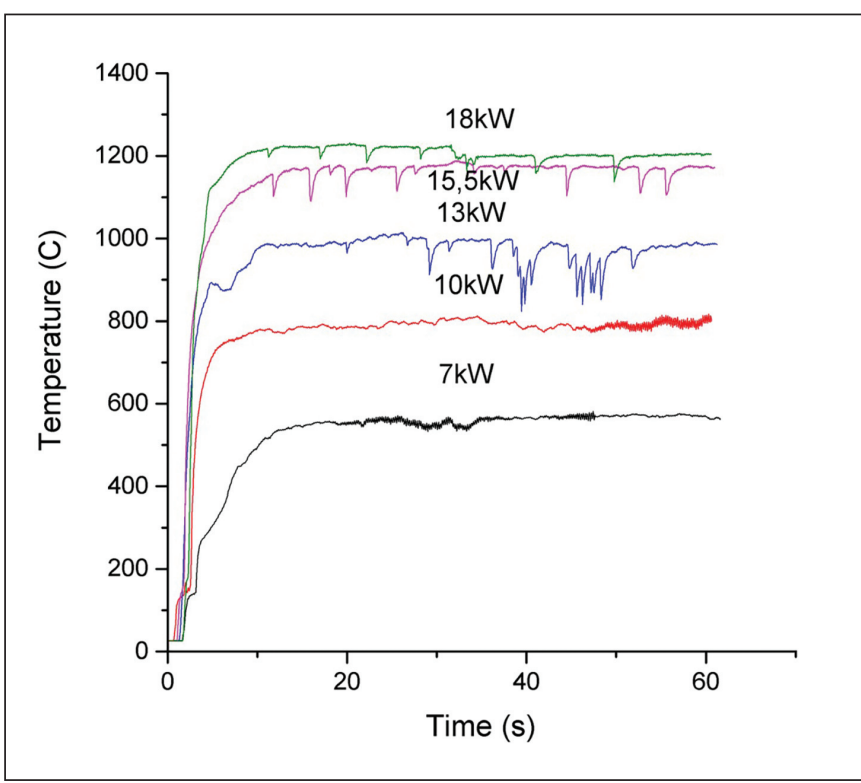

Fig. 6-The heating cycles and steady maximum temperature at a depth of $1.0 \mathrm{~mm}$ in an underwater steel plate as a function of power and time.

well as etching with Nital 2\% solution. Six HV1 microhardness measurements were performed in the HAZ of each sample starting at $0.5 \mathrm{~mm}$ from the surface of the plate and with a distance of $0.5 \mathrm{~mm}$ between indentations - Fig. 4 .

\section{Type 3 Experiments}

Based on the results obtained in the Type 2 experiments, a set of parameters was selected to test their application on a 19-mm-thick V-butt joint that was welded using a gravity feed system inside a hyperbaric chamber in underwater wet conditions at an equivalent depth of $10 \mathrm{~m}$. The chemical composition of the base and weld metals (only the main elements) are given in Table 1. The main welding conditions were as follows: electrode - WW70 commercial oxyrutile-type, $3.25 \mathrm{~mm}$; welding current - 170-190 A constant current; welding voltage $-25-27 \mathrm{~V}$; and welding speed $-3.8 \mathrm{~mm} / \mathrm{s}$.

To check whether the maximum hardness met the AWS D3.6M Class A (< $325 \mathrm{HV}$ ) requirements, only the HAZ of one side of the weld was postheated following the same general conditions adopted in the BOP tests (Fig. 5) except the heating time was $30 \mathrm{~s}$ and a cooling ramp of $60 \mathrm{~s}$ was imposed. The applied power was $18 \mathrm{~kW}$. A HV1 microhardness was measured on both sides of the weld joint, and microstructural analyses were performed in the two regions. All the samples were prepared metallographically following the standard grinding and polishing procedures as well as etching with Nital $2 \%$ solution.

\section{Results and Discussion}

\section{Temperature Measurements}

Temperature measurements at a depth of $1.0 \mathrm{~mm}$ in the plate for the specific conditions used (Fig. 3) showed a strong correlation between the power and maximum

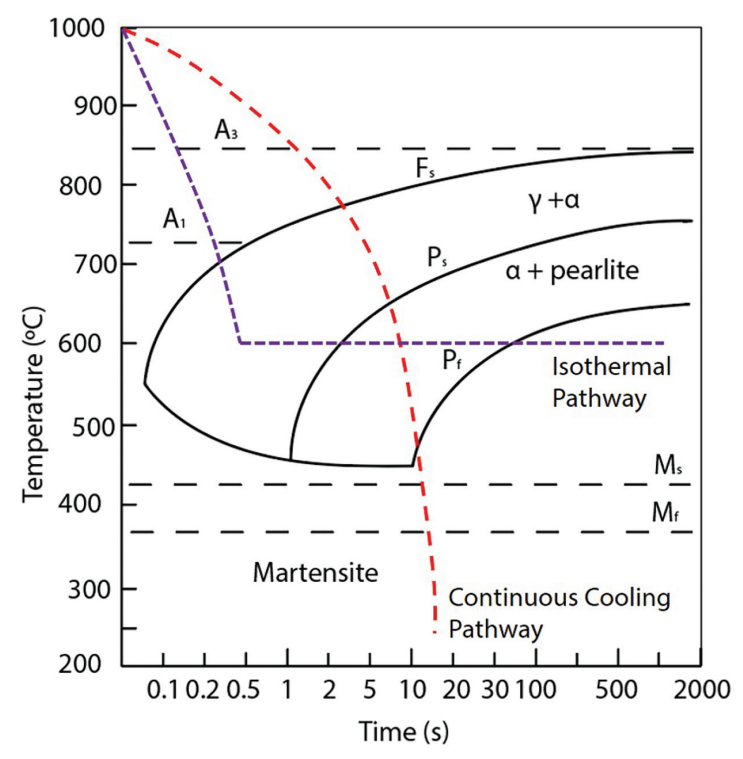

Fig. 7-Approximate CCT diagram for low-carbon steel showing two different pathways to avoid martensite formation.

steady temperature achieved. The thermal cycles showed that it takes about $10 \mathrm{~s}$ to reach maximum temperature after which the heat flow reaches an equilibrium and the temperature remains constant. Figure 6 shows that for the powers $7,10,13,15.5$, and $18 \mathrm{~kW}$, the maximum temperatures stabilized at about $500^{\circ}, 800^{\circ}, 1000^{\circ}, 1100^{\circ}$, and $1200^{\circ} \mathrm{C}$, respectively. However, this equilibrium temperature depends on other variables, such as the mass and shape of the steel plate as well as the dimensions and material of the coil. For $7.0 \mathrm{~kW}$, the maximum temperature reached was about $500^{\circ} \mathrm{C}$. That is ideal for longer PWHT times and when austenitization is avoided. At this temperature, the resulting hardness and microstructure depend only on the time needed for the development of the martensite tempering stages, such as carbon segregation, carbon precipitation, carbides conversion to cementite, austenite decomposition, recovery of dislocation structure, and recrystallization.

As shown in Fig. 6, the power range between 10 and $18 \mathrm{~kW}$ induced the maximum temperature in the plate above the pearlite to austenite phase transformation (A1 temperature). That means, when using these parameters in some region of the plate, martensitic transformation will occur unless the cooling speed is controlled and the final hardness can be even higher than that exhibited before the heat treatment.

Promoting austenite to perlite or bainite transformation can be done by forcing an isothermal transformation at a temperature below $\mathrm{A} 1$ (e.g., $600^{\circ} \mathrm{C}$ with the power of $7 \mathrm{kw}$ ) or by continuous cooling that ends the pearlite transformation before the martensite transformation starting temperature, as represented in the approximate continuous cooling transformation (CCT) diagram in Fig. 7. The isothermal transformation can take longer, and CCT is more practical and has proved to be efficient in controlling the final hardness of the HAZ. The UIPWHT method described here allows both types of control to be applied. 


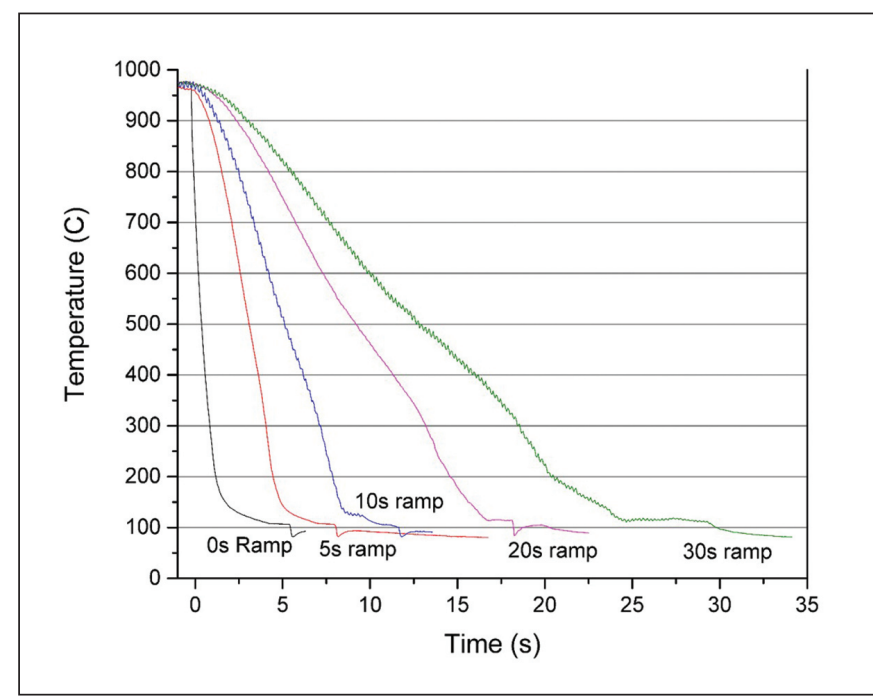

Fig. 8 - Cooling cycles at a depth of $1.0 \mathrm{~mm}$ in the underwater plate as a function of time for different cooling ramps. The applied power was $13 \mathrm{~kW}$.

\section{Cooling Rate Control}

The $\Delta \mathrm{t}_{8 / 5}$ values and cooling rates were measured for five different cooling ramp times (CRTs) at a depth of $1 \mathrm{~mm}$ in the plate, as shown schematically in Fig. 3 . The results shown in Fig. 8 indicate that $\Delta \mathrm{t}_{8 / 5}$ without any cooling ramp was around $0.6 \mathrm{~s}$, and the cooling rate was an impressive $500^{\circ} \mathrm{C} / \mathrm{s}$. This value is in accordance with data reported in previous works (Refs. 7, 8, 13). This cooling rate would certainly promote an amount of martensite formation of the CGHAZ in most of the steels currently applied in the construction of offshore structures. This cooling rate would also explain the HAZ hardness values found between 350 and $450 \mathrm{HV} 1$ in steels with a CE between 0.3 and 0.4 , like the ones used in this work. The UIPWHT method developed by this research group enabled a precise control of the cooling
Table $2-\Delta t_{8 / 5}$ as a Function of the Cooling Ramp Times and Respective Estimated Maximum HAZ Hardness in Steel with the Chemical Composition as Shown in Table 1

\begin{tabular}{cccccc} 
Cooling Ramp Time (s) & 0 & 5 & 10 & 20 & 30 \\
Cooling Rate $\left({ }^{\circ} \mathrm{C} / \mathrm{s}\right)$ & 500 & 200 & 120 & 71.4 & 35.8 \\
$\Delta \mathrm{t}_{8 / 5}(\mathrm{~s})$ & 0.6 & 1.5 & 2.5 & 4.2 & 7.8 \\
$\begin{array}{c}\text { Estimated Maximum } \\
\text { Hardness }(\mathrm{HV})\end{array}$ & 430 & 408 & 368 & 322 & 268 \\
$\begin{array}{c}\text { Average Maximum Hardness } \\
\text { at the HAZ of BOP Welds }\end{array}$ & 442.8 & - & - & - & - \\
\hline
\end{tabular}

rate by selecting the CRT for a linear power reduction from the maximum power to $0 \mathrm{kw}$ in the system.

Table 2 shows the $\Delta t_{8 / 5}$ and cooling rate values as a function of the CRTs selected during the Type 1 experiments. The $\Delta \mathrm{t}_{8 / 5}$ increased with the increase in the cooling ramp and cooling rate times at depth of $1.0 \mathrm{~mm}$ in the plate, reduced from $500^{\circ}$ to $35.8^{\circ} \mathrm{C} / \mathrm{s}$ with the application of a $30-\mathrm{s}$ CRT. The estimated maximum HAZ hardness values for the steel used in the Type 1 and 2 experiments were calculated using the Yurioka method (Ref. 27). This method is based on an empirical equation that can be applied to predict the maximum HAZ hardness through the transformation temperature range as a function of the cooling rates and composition. Table 2 also shows the average maximum hardness values of all measurements performed in the HAZ of BOP welds in the Type 2 experiments. The idea here is not to compare or test the accuracy of the Yurioka method but to show this type of empirical equation can be used to estimate the cooling rate that will produce maximum hardness in the HAZ of wet welds. With that information, the user can program the CRT in the system to ensure, within a certain tolerance, the maximum hardness of the HAZ will be below the limit established by the standard. By applying the Yurioka method to the steel grade used in this work in the Type 1

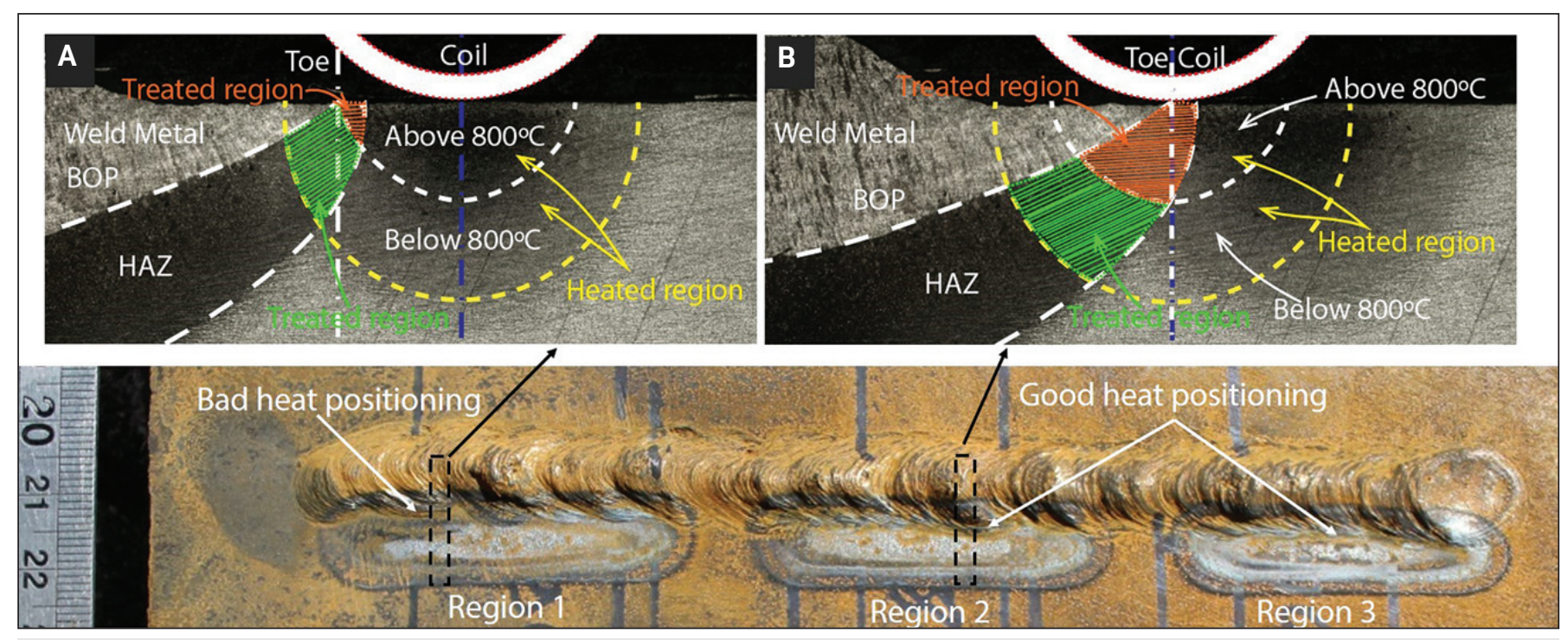

Fig. 9 - Example of the HAZs after UIPWHT was applied to the toe of the BOP welds. Schematics of cross sections show the HAZs with bad $(A)$ and good $(B)$ coil positioning. 


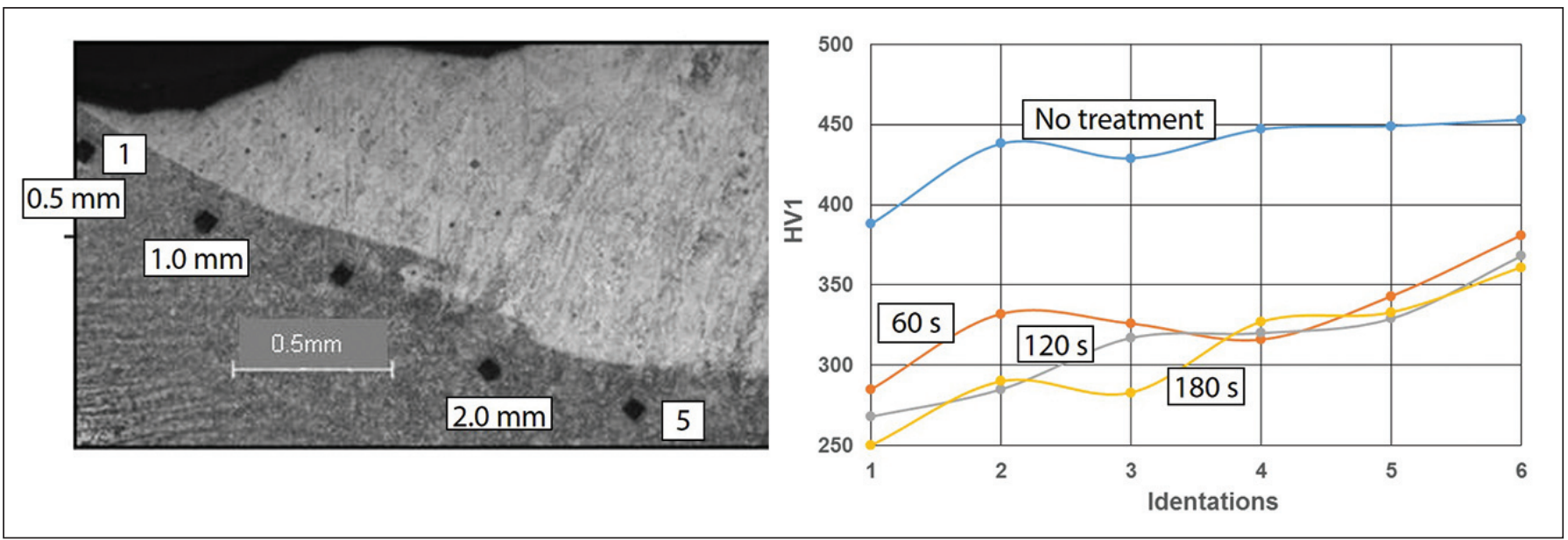

Fig. 10 - Plot of the HAZ microhardness as a function of distance to the surface for different underwater induction holding times. The applied power was $18 \mathrm{~kW}$.

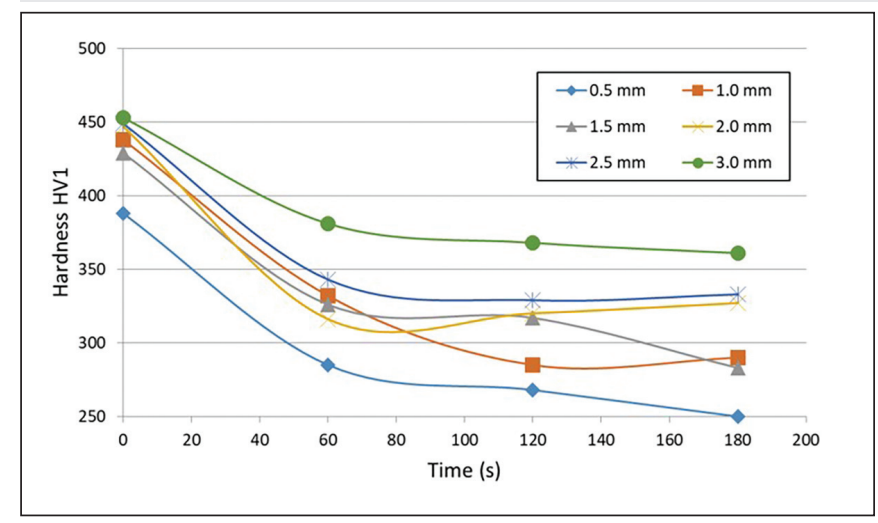

Fig. 11 - Plot of the HAZ microhardness as a function of the holding time for the holding temperature of $1200^{\circ} \mathrm{C}$ (with an applied power of $18 \mathrm{~kW}$ ) at different depths in the HAZ of the BOP welds deposited on Plate 2.

and 2 experiments, a minimum CRT of $20 \mathrm{~s}$ and a cooling rate of $71.4^{\circ} \mathrm{C} / \mathrm{s}$ were estimated to soften the HAZ to a maximum value less than $325 \mathrm{HV}$.

\section{Postheating in the HAZ of BOP Welds}

Tests varying the power (holding temperature on Plate 1) and the holding time (Plate 2 ) of induction heating were performed in wet conditions with the coil positioned in contact with the toe of the BOP wet welds, as described above and illustrated in Fig. 4. The HAZs were postheated under contact surface areas of about $40 \times 8 \mathrm{~mm}-$ Fig. 9 . The hardness results in Figs. 10 and 11 demonstrate that, for an applied power of $18 \mathrm{~kW}$, which corresponds to a holding temperature of $1200^{\circ} \mathrm{C}$, hardness values of around $325 \mathrm{HV} 1$ were found in the fourth indentation located at $2.0 \mathrm{~mm}$ from the plate surface along the weld interface in the HAZ. This proved to be the maximum HAZ depth of the BOP welds deposited on steel plates applied in the Type 2 experiments that can be softened to values below the limit accepted by AWS D3.6M with the maximum allowable power (18 $\mathrm{kW}$ ) in the induction source used in this work. It is possible to increase the depth of the heat in the plate when using an

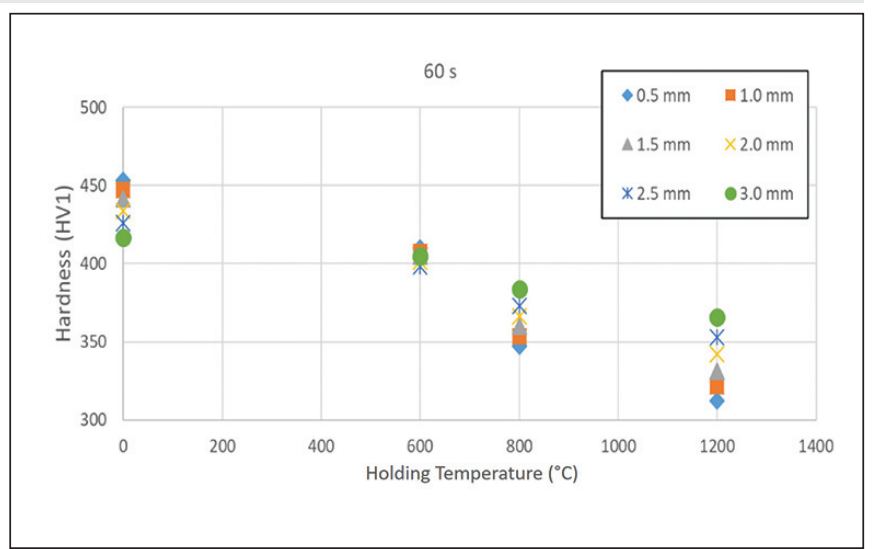

Fig. 12 - Plot of the HAZ microhardness as a function of the holding temperature measured in Plate 1 . The holding time was $60 \mathrm{~s}$.

induction source by controlling the frequency of the current and the shape of the coil as well as increasing the power of the system.

Inversions in the order of the maximum hardness values measured at indentations 2,4 , and 5 can be explained by the variation in the positioning of the coil relative to the toe of the BOP weld - Fig. 9. A proper alignment between the center of the coil and the toe maximizes the size and depth of the treated area of the BOP HAZ - Fig. 9A, B. Bead surfaces irregularities (roughness) like the ones presented in Region 1 can obstruct the contact between the coil and the toe of the weld, leading to a variation in the level of HAZ exposure to heat in the same region. To overcome this, the welder/diver can grind the toe of the weld using a manual grinder to ensure the correct positioning of the coil onto the HAZ of the weld.

Figures 10 and 11 also show a minimum time of $60 \mathrm{~s}$ was required to soften the $\mathrm{HAZ}$ at a depth of $2.0 \mathrm{~mm}$, and the difference between 60,120 , and 180 s was not significant. That means there is a real possibility of reproducing effective TB results using wet PWHT with a heating cycle of $60 \mathrm{~s}$. This time seems to be reasonable for all practical purposes because it is the same order of magnitude as the time spent 


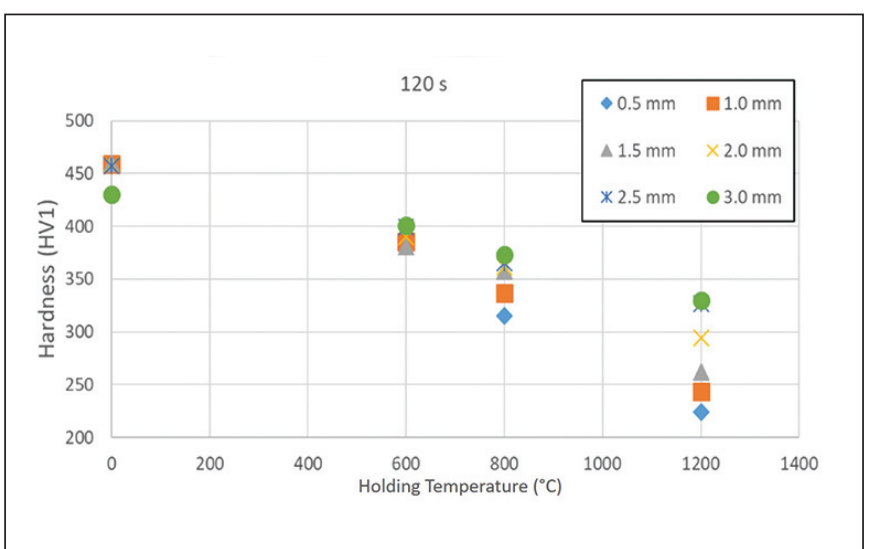

Fig. 13 - Plot of the HAZ microhardness as a function of the holding temperature measured in Plate 2. The holding time was $120 \mathrm{~s}$.

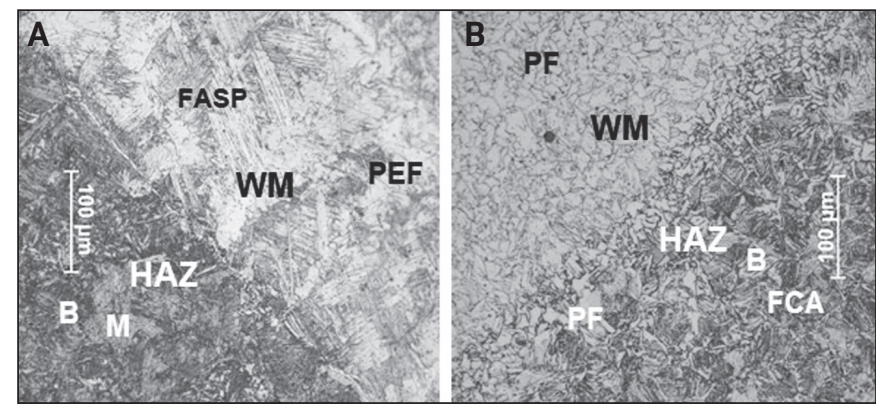

Fig. $15-$ Micrographs showing the untreated $H A Z$ and WM (A) as well as the treated HAZ and WM (B).

by a welder to deposit an underwater wet weld bead.

Figures 12 and 13 show the influence of the holding temperature on the HAZ hardness at different depths in the HAZ of Plates 1 and 2 . The variation in the hardness values in the nontreated condition ( 0 holding temperature) is due to the different measurements in this condition on different samples. Inversions in the order of hardness values are due to a lack of repeatability in positioning the coil at the toe of the BOP welds, as previously explained. The selected holding temperatures of $600^{\circ}, 800^{\circ}$, and $1200^{\circ} \mathrm{C}$ correspond to the powers of 7,10 , and $18 \mathrm{~kW}$, respectively. Holding times of 60 and 120 s were selected.

As expected, higher holding temperatures increased softening for the same holding time. The results shown in Figs. 12 and 13 indicate the $600^{\circ} \mathrm{C}$ temperature did not reduce the HAZ hardness to values below $325 \mathrm{HV}$ when holding times of 60 and $120 \mathrm{~s}$ were applied. Tempering the HAZs of carbon steel usually takes longer than an hour because it is a diffusion-dependent process (Ref. 26). This behavior confirmed that tempering takes longer than the available time in a real UWW procedure. In wet welding, the nonsaturation diving time varies between 1 and $2 \mathrm{~h}$, depending on the depth of the dive. The welding diver can perform the subsequent pass in about $5 \mathrm{~min}$. The results obtained in Type 2 experiments showed that HAZ tempering by induction heating in a wet environment can take longer than the diving time for UWW operations.

The holding temperature of $800^{\circ} \mathrm{C}$ reduced the maximum hardness to values below $325 \mathrm{HV} 1$ at a depth of $0.5 \mathrm{~mm}$ in

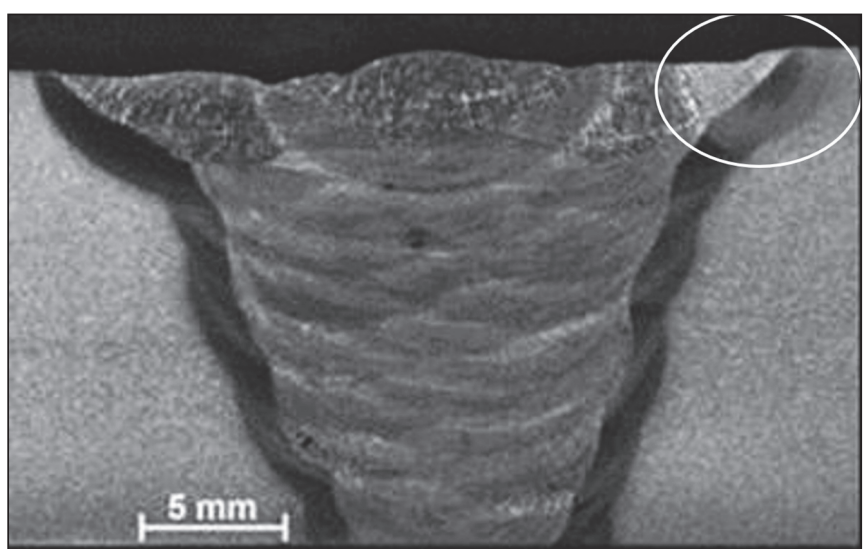

Fig. 14 - Macrograph of the V-groove butt weld joint showing capping passes without (left) and with (right) UIPWHT, respectively. The white ellipse circumscribes the HAZ.

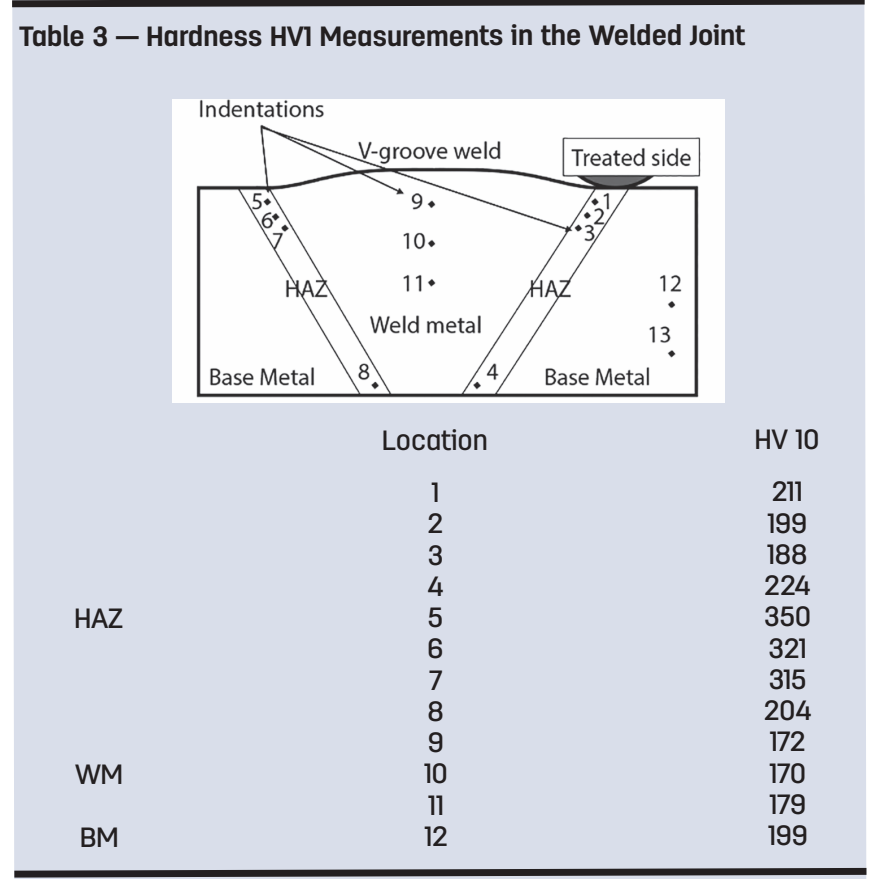

the HAZ when a 120-s holding time was applied. This behavior indicates that deeper HAZs did not reach the A1 transformation temperature, and the holding times of 60 and $120 \mathrm{~s}$ were not enough to temper these regions.

The holding temperature of $1200^{\circ} \mathrm{C}$ was able to reduce hardness to less than $325 \mathrm{HV} 1$ at the depth of $3.0 \mathrm{~mm}$ at a holding time of $120 \mathrm{~s}$, indicating that martensite-to-pearlite phase transformation occurred under these conditions.

One way to increase the depth of the HAZ softening is to promote a holding temperature at the surface of the plate close to the melting point of the steel and deeper regions in the HAZ that will be exposed to temperatures higher that A1. Furthermore, it is important to control grain size in the regions exposed to higher temperatures.

For the 60-s treatment time, only the holding temperature of $1200^{\circ} \mathrm{C}$ was able to reduce hardness under $325 \mathrm{HV} 1$ at a depth of $1.5 \mathrm{~mm}$ in the HAZ.

Considering the main application of the UIPWHT method is to soften the capping passes in a multipass under- 
water wet welded joint, an effective depth of $3.0 \mathrm{~mm}$ in the HAZ should be enough to meet the standard maximum hardness requirements.

\section{Postheating the HAZ of a Capping Pass}

The results of the simulated UIPWHT on a 16-mm-thick multipass butt weld are presented in Figs. 14 and 15 as well as Table 3 . The parameters - $18-\mathrm{kW}$ power (holding temperature of $1200^{\circ} \mathrm{C}$ at $1.0 \mathrm{~mm}$ depth), and 30-s holding time, 60 -s cooling ramp - were applied to the right toe (Fig. 5) of a Vgroove butt weld. The changes of the gray intensities between the two sides (region inside the ellipse in Fig. 14) indicated that both the WM and HAZ microstructures were affected by the heat treatment. Figure $15 \mathrm{~A}$ and $\mathrm{B}$ show the microstructures of untreated and treated regions. Figure 15A was composed predominantly of the following: a HAZ with martensite (M) and bainite (B) as well as a WM with columnar grains of ferrite with aligned second phases (FSAP) and proeutectoid ferrite (PEF). Figure $15 B$ was composed predominantly of the following: a HAZ with polygonal ferrite (PF), bainite (B), and ferrite-carbide aggregates (FCA) as well as a WM of recrystallized polygonal ferrite (PF).

These microstructural changes indicate that high hardness phases were transformed to austenite, and the control of the cooling rate was effective to ensure the perlite/ferrite transformation.

The effectiveness of the heat treatments is confirmed by the hardness measurements shown in Table 3, according to the AWS D3.6M Code's (Ref. 4) recommendations for butt joints during a welding qualification process. The maximum hardness was reduced from $350 \mathrm{HV} 1$ in the HAZ of the capping pass without UIPWHT to $211 \mathrm{HV} 1$ in the treated region.

\section{Conclusion}

An induction power source with a software program to impose specified cooling ramps was developed with successful results. The holding temperatures were measured on a flat surface of an instrumented steel plate at $1 \mathrm{~mm}$ depth. Based on the specific conditions as well as the materials and equipment used in this work, it is possible to conclude the following:

Microhardness measurements performed in the HAZ of BOP and V-groove butt multipass welds indicated the technical feasibility of UIPWHT in terms of meeting the $325 \mathrm{HV}$ maximum criterion.

The maximum depth of the heated region was about 5 $\mathrm{mm}$ and the maximum HAZ in a single BOP weld that UIPWHT was able to soften to the $325 \mathrm{HV}$ maximum was about $2.5 \mathrm{~mm}$. The underwater induction power of $18 \mathrm{~kW}$ with a specific coil/inductor was able to heat subsurface regions (1.0 mm depth) of a steel plate up to a maximum temperature of about $1200^{\circ} \mathrm{C}$.

The proposed UIPWHT was able to control the essential parameters (holding temperature, holding time, and cooling rate) for a successful PWHT of the underwater wet welded HAZ. The optimal set of parameters for each specific power source and accessory has to be determined, and the cooling rates have to be estimated for each particular application.

The proposed UIPWHT enabled the tempering of subsur- face regions in the HAZ of underwater wet welds, but the times required to perform this procedure made its application unfeasible in wet welding. Martensite-to-austenite phase transformation followed by a controlled cooling rate was shown to be the fastest heat treatment to soften a depth up to $2.5 \mathrm{~mm}$ in the HAZ of UWW deposits.

\section{Acknowledgment}

The authors wish to express their gratitude to PETROBRAS - CENPES for their financial support of this project and to the Brazilian Council for Scientific and Technological Development - CNPq for graduate scholarships.

\section{References}

1. Pessoa, E. C. P., Bracarense, A. Q., dos Santos, V. R., Marinho, R. R., Menezes, P. H. R., and Assunção, H. L. 2016. Estudo de aquecimento por indução eletromagnética no tratamento térmico póssoldagem de soldas subaquáticas molhadas. XLII CONSOLDACongresso Nacional de Soldagem, Belo Horizonte, Brazil.

2. Pessoa, E. C. P., Bracarense, A. Q., dos Santos, V. R., Monteiro, M. J., Rizzo, F. C., Marinho, R. R., Vieira, L. A., and Silva, D. B. 2013. Wet welding field trials in shallow waters for structural repairs in floating oil production units. ASME $32^{\text {nd }}$ International Conference on Offshore Mechanics and Arctic Engineering, Nantes, France. DOI: 10.1115/OMAE2013-10097

3. Dos Santos, V. R., Monteiro, M. J., Rizzo, F. C., Barcarense, A. Q., Pessoa, E. C. P., Marinho, R. R., and Vieira, L. A. 2012. Development of an oxyrutile electrode for wet welding. Welding Journal 91(12): 319-s to 328-s.

4. AWS D3.6M:2017, Underwater Welding Code. 2017. Miami, Fla.: American Welding Society.

5. Pessoa, E. C. P., Bracarense, A. Q., dos Santos, V. R., Monteiro, M. J., Vieira, L. A., and Marinho, R. R. 2013. Challenges to develop an underwater wet welding electrode for "Class A welds" classification, as required in the AWS D3.6 code. ASM $9^{\text {th }}$ International Trends in Welding Research: p. 259.

6. Bracarense, A. Q., Pessoa, E. C. P., dos Santos, V. R., Monteiro, M. J., Rizzo, F. C., Paciornik, S., Reppold, R., Domingues, J. R., and Vieira, L. A. 2008. Comparative study of commercial electrodes for underwater wet welding. IIW $2^{\text {nd }}$ Latin American Welding Congress, XXXIV CONSOLDA, São Paulo, Brazil.

7. Tsai, C. L., and Masubuchi, K. 1979. Mechanisms of rapid cooling in underwater welding. Applied Ocean Research 1(2): 99110. DOI: 10.1016/0141-1187(79)90023-3

8. Hasui, A., and Suga, Y. 1979. On cooling of underwater welds. Journal of the Japan Welding Society 48(12): 1077-1083. DOI: 10.2207/qjjws1943.48.1077

9. Fukuoka, T., and Fukui, S. 1993. Analysis for cooling process of underwater welding. Journal of the Marine Engineering Society in Japan 28(12): 767-774. DOI: 10.5988/jime1966.28.767

10. Pan, J., Yang, L., Hu, S., and Chai, S. 2015. Numerical analysis of thermal cycle characteristics and prediction of microstructure in multi-pass UWW. Int. J. Adv. Manuf. Technol. 84: 1095-1102. DOI: 10.1007/s00170-015-7787-6

11. Brown, R. T., and Masubuchi, K. 1975. Fundamental research on underwater welding. Welding Journal 54(6): 178-s to 188-s.

12. Gao, W., Wang, D., Cheng, F., Di, X., Deng, C., and Xu, W. 2016. Microstructural and mechanical performance of underwater wet welded S355 steel. Journal of Materials Processing Technology 238: 333-340. DOI: 10.1016/j.jmatprotec.2016.07.039 
13. Szelagowski, P., and Ibarra, S. 1992. In-situ post-weld heat treatment of wet welds. $24^{\text {th }}$ Annual Offshore Technology Conference, Houston, Tex. DOI: 10.4043/6907-MS

14. Leão, C. A., dos Santos, V. R., and Vaz, M. A. 2003. Emprego do pós-aquecimento na soldagem subaquática molhada. Soldagem \& Inspeção 8(13): 113-117.

15. Yu, L., Saida, K., Hirano, S., Chigusa, N., Mochizuki, M., and Nishimoto, K. 2017. Application of neural network-based hardness prediction method to HAZ of A533B steel produced by laser temper bead welding. Welding in the World 61: 483-498. DOI: 10.1007/ s40194-017-0433-1

16. Fukuda, T., Sumiya, R., Kono, W., Suezono, N., Tamura, M., and Chida, I. 2009. Temper-bead weld by underwater laser beam welding. $17^{\text {th }}$ International Conference on Nuclear Engineering, Brussels, Belgium. DOI: 10.1115/ICONE17-75124

17. Olsen, K., Olson, D. L., and Christensen, N. 1982. Weld bead tempering of the heat-affected zone. Scandinavian Journal of Metallurgy 11(4): 163-168.

18. Fydrych, D., Świerczyńska, A., Rogalski, G., and Łabanowski, J. 2016. Temper bead welding of S420G2+M steel in water environment. Advances in Materials Science 16(4): 5-16. DOI: 10.1515/ adms-2016-0018

19. Fydrych, D., Łabanowski, J., and Rogalski, G. 2013. Weldability of high strength steels in wet welding conditions. Polish Maritime Research 20: 67-73. DOI: 10.2478/pomr-2013-0018

20. Rogalski, G., Fydrych, D., and Łabanowski, J. 2017. Underwater wet repair welding of API 5L X65M pipeline steel. Polish Maritime Research 24(S1): 188-194. DOI: 10.1515/pomr-2017-0038

21. Fydrych, D., Łabanowski, J., Tomków, J., and Rogalski, G. 2015. Cold cracking of underwater wet welded S355G10+N high strength steel. Advances in Materials Science 15(3). DOI: 10.1515/ adms-2015-0015

22. Li, H., Liu, D., Yan, Y., Guo, N., Liu, Y., and Feng, J. 2018. Effects of heat input on arc stability and weld quality in underwater wet flux-cored arc welding of E40 steel. Journal of Manufacturing Processes 31: 833-843. DOI: 10.1016/j.jmapro.2018.01.013

23. Zhang, H. T., Dai, X. Y., Feng, J. C., and Hu, L. L. 2015. Preliminary investigation on real-time induction heating-assisted underwater wet welding. Welding Journal 94(1): 8-s to 15-s.

24. Brätz, O., Henkel, K. M., Klett, J., and Hassel, T. 2019. Induction as heat technology for wet underwater welding of highstrength steels. $7^{\text {th }}$ Conference Underwater Technology. DVS Reports 359, DVS Media GmbH, Düsseldorf, Germany: pp. 5-13.

25. Canale, L. C. F., Yao, X., Gu, J., and Totten, G. E. 2008. A historical overview of steel tempering parameters. Int. J. Microstructure and Materials Properties 3(4/5): 474-525. DOI: 10.1504/IJMMP. 2008.022033

26. Ramirez, J. E., Mishael, S., and Shockley, R. 2005. Properties and sulfide stress cracking resistance of coarse-grained heataffected zones in V-microalloyed X60 steel pipe. Welding Journal 84(7): 113-s to 123-s.

27. Yurioka, N., Okumura, M., Kasuya, T., and Cotton, H. J. U. 1987. Prediction of HAZ hardness of transformable steels. Metal Construction 19(4): 217R-223R.

EZEQUIEL CAIRES PEREIRA PESSOA (ezequielpessoa@letu. edu) is with the Materials Joining Engineering Department, LeTourneau University, Longview, Tex.; ALEXANDRE QUEIROZ BRACARENSE and HENRIQUE LEITE ASSUNÇÃO are with the Mechanical Engineering Department, Universidade Federal de Minas Gerais, Belo Horizonte, Brazil; VALTER ROCHA dos SANTOS and FERNANDO COSME RIZZO are with the Materials Engineering Department, Pontifícia Universidade Católica do Rio de Janeiro, Rio de Janeiro, Brazil; and RICARDO REPPOLD MARINHO is with the PETROBRAS Research Center, Rio de Janeiro, Brazil.

\section{Welding Journal Now Publishing Direct Object Identifier (DOI) Numbers}

Dear members of the welding research community,

Note that in each issue of the Welding Journal Research Supplement, we are including Direct Object Identifier (DOI) numbers with each of the papers published in print and online. A direct object identifier is a unique alphanumeric string assigned by a registration agency (we are using Crossref.org) to identify content and provide a persistent link to its location on the Internet. Our decision to begin assigning a DOl for each paper comes directly from a request by the research community.

As part of our obligation to Crossref.org, we are asked to provide DOI numbers, when available, in the references section of papers. So, if you have submitted a paper to the Welding Journal or are planning on submitting a paper, we ask that you update your references to include DOI numbers whenever possible.

Thank you.

Annette Alonso

Publisher, Welding Journal 